
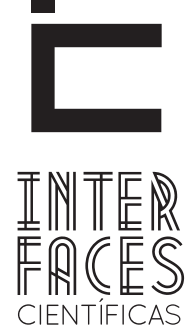

DIREITO

\title{
O DIREITO DE GREVE NO BRASIL E NA ARGENTINA E SUAS LIMITAÇÕES
}

José Araujo Avelino ${ }^{1}$

\section{RESUMO}

O direito de greve é uma conquista dos trabalhadores que depois de lutar por muito tempo, transformou em um direito fundamental consagrado constitucionalmente em muitos países. Contudo, esse direito não ganhou status de caráter absoluto, porque o Estado impôs limitações no exercício desse direito em razão da necessidade da manutenção das atividades e serviços essenciais a ser assegurados à coletividade. Assim, o presente trabalho tem como objetivo anali- sar o Direito de Greve e as suas limitações para o efetivo exercício, tendo como base o direito brasileiro e argentino, para saber como se aplica o instituto em ambos os países.

\section{PALAVRAS-CHAVE}

Greve. Limitações. Direito Fundamental. Conquistas. 


\section{ABSTRACT}

The right to strike is an achievement of workers after struggling for a long time, turned into a fundamental right under the Constitution in many countries. However, this right has not won absoluteness of status because the State imposed limitations on the exercise of this right due to the need for these activities and essential services to be provided to the community. Thus, the present

\section{RESUMEN}

El derecho de huelga es un logro de los trabajadores después de luchar durante mucho tiempo, se convirtió en un derecho fundamental en la Constitución en muchos países. Sin embargo, este derecho no ha ganado carácter absoluto, porque el Estado impone limitaciones al ejercicio de este derecho debido a la necesidad de que estas actividades y servicios esenciales que presta a la comunidad. Por lo tanto, el pre- study aims to analyze the Right to Strike and limitations to effective, based on the Brazilian and Argentine law for how to apply the institute in both countries.

\section{KEYWORDS}

Strike. Limitations. Fundamental Right. Achievements.

sente estudio tiene como objetivo analizar el derecho de huelga y las limitaciones de efectivo ejercicio, basado en la ley brasileña y argentina, para saber cómo si aplica el instituto en ambos países.

\section{PALABRAS-CLAVE}

Huelga. Limitaciones. Derecho fundamental. logros. 


\section{ANTECEDENTES}

Os indivíduos se interagem uns com os outros, compondo-se em um grupo social, capaz de realizar ações coletivas e constituir bases sólidas com objetivo de solucionar conflitos e interesses comuns.

Destacamos, pois, que os grupos sociais se dividem, formando categorias de acordo com os fins e interesses que cada um almeja.

Nesse contexto, de acordo com a melhor doutrina, podemos classificar os grupos sociais como sendo: a) grupos primários, que tem como base a efetividade, incluindo, a família e o lazer; b) grupos secundários, que são formados em grandes espaços, como empregados de uma grande empresa, associados de sindicatos etc. e, c) grupo organizado, que são formados por um determinado segmento de atividade, como por exemplo, uma determinada categoria profissional (BARROS, 2012, p. 1029).

Geralmente, os interesses desses grupos sociais são caracterizados pelo antagonismo, dando-se origem a um conflito coletivo, sendo a greve uma expressão para demonstrar o inconformismo para diversas classes sociais, em especial, a categoria de trabalhadores, objeto do nosso estudo.

Assim, no presente trabalho, se utilizará como metodologia a revisão da legislação brasileira e argentina, levando-se em consideração a evolução histórica no cenário mundial, buscando aporte em obras doutrinárias, com maior enfoque para os juristas dos países envolvidos na análise do estudo proposto.

\subsection{AS PRIMEIRAS GREVES}

Embora existam divergências entre diversos autores quanto ao início da primeira greve no mundo, tem-se noticiado que a primeira grave teria sido com a fuga dos hebreus do Egito, narrado pelo Êxodo, outros relatam que esse movimento da greve foi realiza- do pelos egípcios que trabalhavam no Templo de Mut, quando os trabalhadores se rebelaram por conta do pagamento de salário que era realizado em forma de alimentação, que mal dava para se alimentar (BARROS, 2012, p. 1029).

Outra afirmação foi quanto à retirada dos plebeus de Roma para o Monte Aventino (493 a.C.), motivada por uma greve, embora, aquele movimento tivesse uma conotação política e de protesto, divergindo assim, quem defende que na Fenícia, os trabalhadores, em várias ocasiões declararam greves por melhores condições de trabalho, sendo este último a principal origem da greve (ZARDA, 1972, p. 12).

Por seu turno, na Idade Média, houve uma grande quantidade de agrupamento de trabalhadores clandestinos contra as corporações de ofício na França, na Alemanha e na Itália, o que deu início a criação de legislação proibitiva para a realização de greves, sendo, que o controle se deu precipuamente na sociedade capitalista do período emanado pela Revolução Industrial (Séculos XVIII-XIX), de onde, os trabalhadores eram submetidos a duras condições de trabalho.

O nascimento da indústria só fez aumentar a concentração da massa do proletariado, que estava associada à precariedade da situação socioeconômica dos trabalhadores frente aos patrões, contribuiu para a formação de associações de profissionais com a finalidade de organizar os trabalhadores para reivindicar aos empresários, melhorias nas condições de trabalho.

Embora, o sistema liberal da época não permitisse a realização de greve, porque não reconhecia a vida em grupos sociais organizados e, consequentemente, também, não reconhecia os direitos coletivos, pois, não queria que o Estado interviesse nas questões econômicas das atividades empresárias. Mesmo assim os trabalhadores exerciam o direito de greve, porém, eram reprimidos, porque não existia norma própria. E, assim, os empresários diziam as regras rígidas a ser observadas pelos trabalhadores. 
A Lei Chapellier de 1791 e o Código Penal de 1810 da Inglaterra e da França, consequentemente, foram os que mais reprimiram o direito de greve, pois, consideravam um delito.

Por parte igreja, foi divulgada por meio da Carta Encíclica do Papa Leão XIII (1891), a primeira manifestação aberta com objetivo de proteger os trabalhadores e as entidades sindicais, no período em que o Estado liberal dominava o cenário econômico do mundo.

Por sua vez, em Portugal, na mesma época da Carta Papal, quem praticava a greve não recebia punição, embora, a lei fizesse referência à pena aos praticantes. $\mathrm{Na}$ Itália, a greve foi considerada um delito até a promulgação do Código Zanardelli, revogando a pena de delito para os grevistas, sendo que mais tarde (1926) no regime corporativo, a greve voltou a ser considerada um delito. Finalmente, a Constituição Republicana da Itália (1948) no seu artigo 40, revogou o delito para assegurar o direito de greve aos trabalhadores.

\subsection{FASES DA GREVE}

Observamos que para o reconhecimento do direito de greve, em prol dos trabalhadores, foi necessário observar duas fases:

a) fase da proibição - onde o trabalhador cumpria dupla qualificação. A primeira era o ilícito civil, cuja consequência para quem fizesse a greve era resolução do contrato de trabalho. E, no segundo momento, o trabalhador era reprimido penalmente;

b) fase da tolerância - embora o exercício da greve nessa fase tenha abolido o ilícito penal, continuou vigente o ilícito civil, até o reconhecimento do direito de exercício da greve no plano constitucional, vista como forma legítima de defesa dos trabalhadores frente aos empresários.

Em países de regimes socialistas, o exercício do direito de greve é proibido, sob o argumento de que o proletariado já se encontra no poder e, por isso, não justifica fazê-la, embora, fosse um argumento fracassado (CUERVA, 1970, p. 757).

No plano internacional, a greve não é disciplinada pela Organização Internacional do Trabalho (OIT), porque entende que o trabalhador deverá ser vinculado ao direito de sindicalização. Entretanto, a Declaração Universal dos Direitos Humanos prevê, de forma implícita, o direito de greve ao estabelecer, no seu artigo $X X, n^{\circ} 1$, que toda pessoa tem direito à liberdade de reunião e associação pacíficas, bem como no artigo XXIII, $n^{\circ} 4$, ao garantir que toda pessoa tem direito a organizar sindicatos e a neles ingressar para proteção de seus interesses, que somente foi confirmada pela Carta Social Europeia e o Pacto sobre direitos Econômicos, Sociais e Culturais, assinado em Nova York (1966), ao trazer a previsão do direito de greve.

\subsection{A GREVE NA VISÃO SOCIAL E JURÍDICA}

Enquadrada como um fenômeno social, a greve tem origem na formação de grupos de trabalhadores que vivenciou ao longo do tempo uma trajetória penosa, tendo como resultado o reconhecimento em vários países como sendo um direito fundamental.

Por ser um fenômeno social, a greve possui caráter coletivo, ou seja, para que a greve pudesse existir, necessariamente, os trabalhadores tinham que ficar vinculados à atuação dos sindicatos por meio de manifestações e negociações como forma de buscar melhores condições de trabalho e tutela de seus direitos.

Desta maneira, o direito coletivo passou a ser reconhecido como sendo um mecanismo do fator de produção entre o capital e o trabalho e, por isso, a empresa deixou de ser "feudo do patrão", porque a empresa tem o direito a obtenção do lucro, mas por outro lado, o trabalhador tem direito de viver dignamente com o salário justo que é fruto de seu trabalho. 
No campo jurídico, encontramos sustentação na própria constituição de um país ao afirmar que todos trabalhadores sejam tratados de forma igual, juntamente com os demais. Todavia, se as regras da empresa são injustas e não encontra acordo para solucionar o desnível nas condições de trabalho, temos assim, "a paralisação das atividades como uma solução para alcançar o fim almejado, pois, estará em consonância com a função social da propriedade e com os mandamentos da justiça social” (BARROS, 2012, p. 1032).

No campo jurisdicional, a Justiça do Trabalho é competente para julgar e resolver os conflitos relativos ao direito de greve no Brasil, nos termos previstos no artigo 114, inciso II, da Constituição Federal de 1988. Do mesmo modo, na Argentina, os casos não resolvidos no âmbito administrativo, serão decididos pela Justiça do Trabalho.

Em relação aos efeitos do contrato de trabalho, o trabalhador que estiver no gozo do direito de greve, o contrato de trabalho ficará suspenso até que retome as atividades para o empregador não podendo ser dispensados durante esse período.

\subsection{CONCEITOS DE GREVE}

Como vimos o direito de greve no plano internacional não foi objeto de um convênio elaborado pela OIT, porque é um direito que se encontra vinculado a outro direito: o direito de sindicalização. Assim, como a Declaração Universal dos Direitos Humanos trouxe a previsão do direito de greve, a Carta Social Europeia e o Pacto sobre direitos Econômicos, Sociais e Culturais, assinado em Nova York (1966), confirmaram o exercício do direito de greve pelos trabalhadores, cabendo ao Estado a disciplina por meio de normas.

Para melhor situar o que é greve é necessário socorrermos à doutrina para conceituá-lo, pois, muitas das vezes a norma não traz uma definição clara do instituto.

Com base nisso, a seguir, apresentaremos alguns conceitos do instituto da greve, com base na melhor doutrina que temos disponível.

De acordo com Arnaldo Sussekind (2000, p. 37),

De acordo com Arnaldo Sussekind, citando Mário Deveali, a greve consiste na "abstenção simultânea do trabalho, concertada pelos trabalhadores de um ou mais estabelecimentos, ou de suas seções, com o fim de defender os interesses da profissão" (SUSSEKIND, 1999, p. 37).

A greve, também, pode ser entendida, de acordo com Maurício Godinho Delgado (2014, p. 1475), como:

[...] a paralisação coletiva provisória, parcial ou total, das atividades dos trabalhadores em face de seus empregadores ou tomadores de serviços, com o objetivo de exercer-lhes pressão, visando à defesa ou conquista de interesses coletivos, ou com objetivos sociais mais amplos.

Para Alice Monteiro de Barros (2012, p. 1033), a greve não é simplesmente uma paralisação do trabalho, mas sim, "uma cessão temporária do trabalho, com o objetivo de impor a vontade dos trabalhadores ao empregador sobre determinados pontos".

Segundo Julio Armando Grisolía (2013, p. 862) a greve é:

[] un derecho que la Constitución concede a los gremios, y consiste en la abstención colectiva y concertada de la prestación laboral, con carácter temporal y con abandono del lugar de tareas, como forma de presión sobre la voluntad del empleador, con el propósito de conseguir un beneficio mediante la sanción de una nueva disposición o la reforma de una vigente, o bien al complimiento de una norma en vigor.

Assim, diante dos diversos conceitos apresentados acima, podemos dizer que a greve, embora seja um di- 
reito, e ao mesmo tempo a possibilidade do exercício de uma liberdade, não pode ser entendida como um direito absoluto do trabalhador, pois, a própria norma impõe limitações para o exercício desse direito.

\section{DIREITO DE GREVE NO BRASIL}

O exercício do direito de greve no Brasil não foi tão diferente em relação aos europeus, tendo passado, também, pelo período da proibição, como o advento da Constituição de 1937, que passou a considerar a greve o lockout, mecanismos muito nocivos ao capital e ao trabalho, em razão dos grandes prejuízos e das repercussões que causavam na sociedade, principalmente na economia.

Em 1946, por meio do Decreto-Lei no 9.070, o direito de greve voltou a ser restabelecido e recepcionado pela Constituição de 1946, embora, tenha ocorrido proibição da greve nas atividades fundamentais do Estado prestadas à coletividade.

Em seguida (1964), a Lei $n^{0} 4.330$, estabeleceu procedimentos e exigências para o exercício do direito de greve, sendo que o curioso foi a não proibição da greve nos serviços essenciais, que somente no ano de 1967 com a nova Constituição, passou a ser proibida a greve nas atividades essenciais do serviço público.

Ocorre que somente em 1978, por meio do Decreto-Lei $n^{0} 1.632$, que passou a estipular quais eram os serviços públicos considerados essenciais e, com isso, praticamente, toda atividade pública passou a ser considerada essencial pela norma, que inviabilizava o exercício da greve pelos trabalhadores, diante do excesso estabelecido pela lei.

Finalmente, com a Constituição de 1988, no seu artigo $9^{\circ}$, o direito de greve foi restabelecido, inclusive, nos serviços ou atividades consideradas essenciais, deixando a cargo de uma lei regulamentadora definir o que são atividades essenciais.
Por seu turno, o artigo 37, inciso VII da Constituição Federal de 1988, dispõe que o direito de greve no serviço público será exercido mediante os termos e os limites definidos por lei específica.

Acontece que, atualmente, no Brasil, a greve é disciplinada por meio da Lei no 7.783/1989 que, no seu artigo 10, trouxe o rol das atividades e serviços considerados essenciais.

O principal problema é que, a lei em comento, foi criada para ser aplicada nas relações do Direito Privado, ficando as atividades regidas pelo Direito Público de fora desta lei.

É claro, que é função do Poder Legislativo elaborar as leis e, nesse aspecto, temos uma omissão legislativa. Nesse caso, como fica uma greve deflagrada por servidores públicos que são regidos pelo Direito Público?

Utilizando-se da proteção constitucional, prevista no artigo $5^{\circ}$, inciso LXXI, o Supremo Tribunal Federal, visando dar efetividade à omissão legislativa, em julgamento dos Mandados de Injunção - MI no 670, 708 e 712 em 2007, decidiu, que enquanto faltar lei de greve para disciplinar o serviço público, serão aplicadas as regras da lei de greve do setor privado, ou seja, tanto para o Direito Privado, quanto para o Direito Público, se aplica a mesma lei de greve (Lei $n^{0} 7.783 / 1989$ ) para todos os trabalhadores, sejam de serviço privado ou público, até o fechamento deste trabalho.

\subsection{LIMITAÇÕES DO EXERCÍCIO DO DIREITO DE GREVE NO BRASIL}

A Constituição brasileira protege o direito de greve, contudo, essa proteção não tem caráter irrestrito e absoluto, porque a própria norma impõe limitação no exercício deste direito.

Com razão o legislador. 0 Estado não pode parar em virtude de movimento grevista, embora, seja um direito constitucionalmente assegurado, mas os direitos fundamentais, como à vida, à liberdade, à igualda- 
de, à segurança e à propriedade, não podem se tornar refém desses grupos, porque, o objetivo é garantir a efetividade desses direitos à população.

O exercício do direito de greve, principalmente nos serviços essências, devem ocorrer em harmonia com os interesses da coletividade e não interesses coletivos difusos.

Mas, afinal, o que a Lei de Greve brasileira, considera como serviços essenciais?

De acordo com o artigo 10 da Lei $n^{0} 7.783 / 1989$ são considerados serviços ou atividades essenciais:

I - tratamento e abastecimento de água; produção e distribuição de energia elétrica, gás e combustíveis;

II - assistência médica e hospitalar;

III - distribuição e comercialização de medicamentos e alimentos;

IV - funerários;

$\mathrm{V}$ - transporte coletivo;

$\mathrm{VI}$ - captação e tratamento de esgoto e lixo;

VII - telecomunicações;

VIII - guarda, uso e controle de substâncias radioativas, equipamentos e materiais nucleares; IX - processamento de dados ligados a serviços essenciais;

$X$ - controle de tráfego aéreo;

XI - compensação bancária.

Ainda, de acordo com a lei, nos serviços ou atividades essenciais, os sindicatos, os empregadores e os trabalhadores ficam obrigados, de comum acordo, a garantir, durante a greve, a prestação dos serviços indispensáveis ao atendimento das necessidades inadiáveis da comunidade.

Portanto, os serviços que coloquem em perigo iminente a sobrevivência, a saúde ou a segurança da população são considerados inadiáveis e, não poderão ser paralisadas durante o período da greve em sua totalidade.
Cumpre ainda, observar, que o exercício do direito de greve deve obedecer aos procedimentos legais. Para que uma greve seja considerara legal, é necessário que tenha ocorrido uma negociação frustrada entre trabalhadores e empregadores ou impossibilidade de recurso via arbitral. Além disso, deve haver uma assembleia geral convocada pela entidade sindical para a deliberação ou não da greve.

Em sendo aprovada a greve na assembléia geral, o sindicato deverá fazer a comunicação prévia ao sindicato patronal e as empresas interessadas num prazo de quarenta e oito horas de antecedência.

O sindicato deve enviar comunicação da greve nos serviços ou atividades essenciais com antecedência mínima de setenta e duas horas da paralisação. Nas atividades não essenciais o prazo é de quarenta e oito horas.

A responsabilidade pelos atos praticados, ilícitos ou crimes cometidos, no curso da greve, será apurada, conforme o caso, segundo a legislação trabalhista, civil ou penal, depois da efetiva apuração por parte do Ministério Público.

\section{DIREITO DE GREVE NA ARGENTINA}

Na metade do século XIX a comunidade de obreiros, comandado por grupos socialistas e anarquistas chegados da imigração europeia, começou a desenvolver os movimentos sociais, sendo que somente ao longo do século XX desenvolveu e consolidou o modelo sindical na Argentina.

Assim, o direito de greve começou a ser reconhecido por meio do Comitê de Liberdade Sindical (1952) e pela Comissão de Expertos na Aplicação de Convênios e Recomendações (1959), como um direito fundamental dos trabalhadores e das organizações sindicais.

É um direito que está previsto na Constituição Nacional em seu artigo 14 bis, conferido as associações sindicais com personalidade gremial, embora, 
[...] a Suprema Corte da Província de Buenos Aires, no caso Leiva, Horacio y otro v. Swift Armour SA (06/07/1984) tenha convalidado uma greve realizada por um grupo de trabalhadores, porque estes, estavam vedados a participar de atividade sindical. (GRISOLÍA, 2013, p. 863).

Diversos instrumentos normativos foram sucedendo ao longo do tempo para conferir aos sindicatos o direito de se organizar com os trabalhadores para a realização das greves no país. Para melhor ilustrar, desde 1958, as leis de associações sindicais foram se aperfeiçoando, começando com a Lei 14.455, depois, a Lei 20.615, em seguida, a Lei 22.105 e, por fim, a Lei 23.551 que se encontra em vigor.

Atualmente, o direito de greve na Argentina é regido através da Lei n 25.877 de 2006, que dentre outras atribuições, trouxe o rol dos serviços essenciais a ser prestados para a coletividade sem a interrupção.

Tanto a doutrina, quanto a jurisprudência Argentina, ainda, diverge a respeito da titularidade do exercício do direito de greve. Existem duas posições para essa questão: a) a primeira posição diz que a titularidade do exercício do direito de greve é de competência da associação sindical de trabalhadores com personalidade jurídica gremial; b) a segunda posição é que existem outros titulares capazes de exercer o direito de greve, como por exemplo, um grupo de trabalhadores ou até mesmo sindicato simplesmente inscrito. No entanto, o que tem prevalecido é a primeira hipótese, sob o fundamento do artigo $5^{\circ}$, inciso “d”, da Lei $n^{0} 23.551$, ser bastante taxativo.

A diferença básica entre a associação sindical com personalidade gremial e, associação sindical simplesmente inscrito é que, o primeiro possui titularidade de direito coletivo, entre outros requisitos, a exigência do seu tempo de mínimo de seis meses de constituição, número mínimo de $20 \%$ de afiliados, conforme artigo 25 da lei e, o segundo não possui titularidade de direito coletivo em razão da simplificação para aquisição da personalidade jurídica, como previsto no artigo 23 da Lei n² 23.551.
Importante destacar que tanto o "Ministério do Trabalho, quanto a Justiça do Trabalho pode declarar ilegal a greve" (GRISOLÍA, 2013, p. 863), ao contrário do Brasil, que somente a Justiça do Trabalho tem essa atribuição.

\subsection{LIMITAÇÕES DO EXERCíCIO DO DIREITO DE GREVE NA ARGENTINA}

Como já afirmado anteriormente, o direito de greve é uma conquista alcançada pelos trabalhadores ao longo da história e, por conseguinte, se traduziu num direito humano fundamental garantido pela Constituição. No entanto, esse direito, não pode ter o status de um "direito absoluto", porque está sujeito a uma regulação específica para o exercício do direito de greve, até mesmo para proteger os direitos da sociedade não envolvida.

Sabemos que o trabalhador faz greve, porque busca melhores condições de vida e, não porque não pretende trabalhar. A conquista de um direito perante o empregador, só se concretiza quando é utilizado esse meio de pressão. Do contrário, nada acontece em razão da posição econômica que se encontra um e outro.

A greve deve ser utilizada pelo trabalhador como último recurso. Assim, como no Brasil, na Argentina, também, deve haver uma "Conciliação Prévia" entre trabalhador e empregador.

Observa-se, atualmente, que na Argentina, essa obrigatoriedade da conciliação prévia, tem causado muita instabilidade jurídica em razão do descumprimento da regra por parte de algumas categorias de trabalhadores. É bastante comum a realização de greve de forma instantânea, como por exemplo, as constantes interrupções de ruas e avenidas por trabalhadores de indústrias, caminheiros, transportes, entre outros, sem o cumprimento do que a lei determina.

Mas quais são as limitações para o exercício do direito de greve na Argentina? 
Em primeiro lugar, de acordo com o regramento da Lei $n^{0} 23.551$, só quem tem a titularidade para poder negociar em nome dos trabalhadores são os sindicatos com personalidade gremial.

A segunda regra diz respeito aos serviços considerados essenciais que não podem deixar de ser prestados à população.

Mas, quais são os serviços considerados essenciais na Argentina?

Antes, vigorava o Decreto 2184/90, que trazia um rol de serviços essenciais. No entanto, a Lei $n^{\circ}$ $25.877 / 2004$, por meio do seu artigo 24 , veio a estabelecer nova lista dos serviços essenciais considerados na Argentina:

Cuando por un conflicto de trabajo alguna de las partes decidiera la adopción de medidas legítimas de acción directa que involucren actividades que puedan ser consideradas servicios esenciales, deberá garantizar la prestación de servicios mínimos para evitar su interrupción. Se consideran esenciales los servicios sanitarios y hospitalarios, la producción y distribución de agua potable, energía eléctrica y gas y el control del tráfico aéreo.

Una actividad no comprendida en el párrafo anterior podrá ser calificada excepcionalmente como servicio esencial, por una comisión independiente integrada según establezca la reglamentación, previa apertura del procedimiento de conciliación previsto en la legislación, en los siguientes supuestos:

a) Cuando por la duración y extensión territorial de la interrupción de la actividad, la ejecución de la medida pudiere poner en peligro la vida, la seguridad o la salud de toda o parte de la población.

b) Cuando se tratare de un servicio público de importancia trascendental, conforme los criterios de los organismos de control de la Organización Internacional del Trabajo.

O exercício do direito de greve, também, exige que os trabalhadores, por meio do sindicato, cumpra alguns procedimentos antes que a mesma seja iniciada, como: a greve; b) Que o conflito tenha submetido antes a Conciliação, mediação ou arbitragem;

c) Observância do quorum e aprovação da greve pela maioria dos trabalhadores;

d) Que a votação tenha ocorrido de forma secreta;

e) Respeitar o regulamento de segurança e prevenção de acidentes contra os próprios trabalhadores e as pessoas;

f) Manter um serviço mínimo em funcionamento em casos específicos, como os essenciais;

g) A garantia da liberdade e direitos dos grevistas, como por exemplo, não ser dispensados pelo empregador durante a greve.

Nos casos em que a greve seja declarada ilegal pelo não cumprimento dos procedimentos legais "la associación sindical que la promovió puede ser pasible de sanciones por el Ministerio de Trabajo (órgano de aplicación). Esa sanción puede consistir en una suspensión de la personería gremial e incluso de su cancelación" (GRISOLÍA, 2013, p. 864). Significa dizer, que o sindicato tanto pode ser suspenso temporariamente, como ter seu registro cancelado em caso do não cumprimento das normas.

\section{CONSIDERACÕ̃ES FINAIS}

Na presente pesquisa literária, constatamos que o direito de greve nasceu com a interação dos trabalhadores por meio de formação de grupos sociais, com objetivo de solucionar os conflitos e melhorar as condições de trabalho impostas pelos capitalistas ao longo da história.

0 direito de greve sempre foi uma ação mal vista pela sociedade capitalista, inclusive, sendo proibida em países socialistas. 
Depois que a Declaração Universal dos Direitos Humanos passou a considerar que toda pessoa tem direito à liberdade de reunião e associação pacíficas e que toda pessoa tem direito a organizar sindicatos e a neles ingressar para proteção de seus interesses, sendo acatada pela Carta Social Europeia e o Pacto sobre direitos Econômicos, Sociais e Culturais, o direito de greve passou a ser considerado como um direito fundamental.

Vimos que o Direito de Greve no Brasil e na Argentina é uma garantia prevista pelas Constituições de ambos os países. No entanto, há uma diferença enquanto a regulamentação da greve: na Argentina a greve é disciplinada por lei, tanto para iniciativa privada, como para o setor público. No Brasil, há apenas uma lei para o setor privado. Nesse caso, há uma omissão legislativa quanto à elaboração da lei para os empregados do setor público. No entanto, o Supremo Tribunal Federal do Brasil, autorizou a aplicação da lei de greve da iniciativa privada, também no setor público, enquanto uma norma específica seja sancionada.

Observamos que um dos requisitos básicos para a validade da greve é que tenha ocorrido antes uma negociação prévia, entre os sindicatos dos trabalhadores e os empregadores.

No que diz respeito à titularidade para negociação da greve, constatamos uma diferença entre os dois países. No Brasil, o sindicato da categoria, desde que devidamente constituído, pode realizar a negociação coletiva, enquanto que na Argentina, somente o sindicato da categoria com personalidade gremial está autorizado. Os demais sindicatos, mesmo registrados, não possuem capacidade de negociação, embora façam parte da categoria profissional.

Em relação à limitação do direito de greve, constatamos que em ambos os países há imposição restritivas aos grevistas e protetivas à população, principalmente, no que diz respeito a atividades e serviços considerados essenciais, embora, haja diferença em ambas as legislações no diz respeito ao que é essencialidade num país, pode não ser no outro.

Constata-se, também, que em ambos os países, especialmente, na Argentina, os trabalhadores, exercem pressão para negociar com os empregadores por meio não legal, como é o caso de interrupções de vias públicas.

Por fim, o direito de greve não é uma garantia constitucional absoluta do trabalhador, é causa de suspensão temporal do contrato de trabalho e, não enseja a dispensa por justa causa, porém, faculta ao empregador o corte de salário pelo período de duração da greve em razão da ausência do trabalhador na execução do serviço.

\section{REFERÊNCIAS}

BARROS, Alice Monteiro de. Curso de Direito do Trabalho. 8.ed. São Paulo: LTr, 2012.

CUERVA, Mario de La. Derecho Mexicano del Trabajo. Tomo I, México: Porrúa, 1970.

DELGADO, Maurício Godinho. Curso de Direito do Trabalho. 13.ed. São Paulo: LTr, 2014.

GRISOLIA, Julio Armando. Manual de Derecho Laboral. Buenos Aires: Abeledo Perrot, 2013.

LIMA, Francisco Meton Marques de. Elementos de direito do trabalho e processo trabalhista. 14.ed. São Paulo: LTr, 2013.

SUSSEKIND, Arnaldo. Convenções da OIT. São Paulo: LTr, 1994.

SUSSEKIND, Arnaldo. Responsabilidade pelo abuso do direito de greve. Revista da Academia Nacional de Direito do Trabalho, ano I, n.1, 1993.

ZARDA, D.L. El derecho de huelga. Tucumán: Universidad Nacional de Tucumán, 1972. 
1. Advogado, professor efetivo de Direito do Trabalho e Processo do Trabalho e Seguridade Social na Universidade do Estado da Bahia. Pós-Graduado em Direito Eleitoral e Processual Eleitoral pelo Centro Universitário Claretiano (São Paulo - 2007), Pós-Graduado em Direito do Trabalho pela Universidade Cândido Mendes (Rio de Janeiro - 2014), Mestrando em Direito Laboral e Relações Internacionais Laborais na Universidad Nacional de Três de Febrero - UNTREF e Doutorando regular em Direito do Trabalho na Universidade de Buenos Aires. 